\title{
Effect of Telehealth System on Glycemic Control in Children and Adolescents with Type 1 Diabetes
}

Esra Döğer, Rukiye Bozbulut, A. Şebnem Soysal Acar, Şebnem Ercan, Aylin Kılınç Uğurlu, Emine Demet Akbaş, Aysun Bideci, Orhun Çamurdan, Peyami Cinaz

Gazi University Faculty of Medicine, Department of Pediatric Endocrinology, Ankara, Turkey

Address for Correspondence: Rukiye Bozbulut MD, Gazi University Faculty of Medicine, Department of Pediatric Endocrinology, Ankara, Turkey

E-mail: dyt_rukiye@hotmail.com

ORCID ID: orcid.org/0000-0003-4317-9226

Conflict of interest: None declared

Received: 07.02.2018

Accepted: 17.07 .2018

What is already known on this topic?

In the treatment of diabetes, diabetes education and communication with the diabetes team is as important as medical treatment. Telehealth systems facilitate communication with the diabetes team.

What this study adds?

The use of telehealth systems in Turkish children and adolescents with Type 1 diabetes mellitus has improved glycemic control.

\section{Abstract}

Objective: A close diabetes team-patient relationship is required for establishing a well metabolic control. The purpose of this study is to research the effect of telehealth system developed by the diabetes team on the diabetes control.

\section{Methods:}

The study was carried out between June 2015 and January 2016 at the Gazi University Pediatric Endocrinology Department. The Telehealth system was developed by the diabetes team and the demographic characteristics, frequency of use and HbA1c changes of diabetic patients (type 1) using this communication network were noted. Results: Eighty-two of the patients used The Telehealth system, 43(52.4\%) female and 39 (47.6\%) male with a mean age of $10,89 \pm 4$ years. $14(17.1 \%)$ of the cases were pump therapy and $59(72.0 \%)$ were carbohydrate counts. The individuals with diabetes or their families prefer Whatsapp which is an instant messaging application at most (57.3\%), contact with diabetes education nurse at most (32.9\%) and consult with the diabetes team about insulin doses and blood glucose regulation at most (42.7\%). At the beginning of the study, HbA1c level was rarely used cases $(n=34)$ in the teleheath system $9.1 \%$, and frequently used cases were $8.3 \%$. HbAlc values after 6 months were lower in those individuals calling frequently $(\mathrm{p}<.000)$.

Conclusions: Increase in frequency of counselling to the diabetes team caused the blood glucose control of individuals with diabetes. Telehealth system is a useful system in early detection of the changes and intervention in the status of individual with diabetes, enhancing the patient's self care.

Key words: Type 1 diabetes, telehealth, diabetes team, HbA1c

\section{Introduction}

Diabetes management is a demanding situation (1). Insulin injection, healthy eating style developed for the diabetes and physical activity are important in diabetes management and the individuals with diabetes should learn how to keep the balance between these factors (2). A close health professional-patient relationship,

individualized care and education are must for reaching a good glysemic level in case of the individuals with diabetes (3). It's reported that educational interventions in the children and adolescents with diabetes enhance the glycemic control and psychosocial results (4).

Diabetes education should cover the child with diabetes and his/her family and should be provided by a team of professionals formed of doctor, nurse, dietitian, and psychologist (5). The individuals with diabetes should contact the diabetes team more frequently to maintain the normal interval in the blood glucose levels and prevent complications of diabetes and should access to health services continuously $(2,3)$. However, reasons such as failure of increase in the number of health professionals evenly while the number of patients with diabetes gradually increasing, patient diversity observed in the polyclinics, time limitation cause the traditional 
interventions to be completely inadequate in self-management of patients $(6,7)$. Classical education fails to satisfy due to limitation in healthcare resources, increasing health costs, limited knowledge of patients (8). Moreover, the rural children with diabetes have difficulty in accessing to healthcare because of long distance and transport costs and this situation causes them to receive undertreatment $(2,6)$. Providing health information by communication technologies enables flexible time and space means in accessing to healthcare, decrease in polyclinic visits, decrease in stigmatizing, repetition of education when necessary and decrease in hospital care costs (9-12).

The use of information technology and providing online education are suggested for regular and continuing education (2). Ever widespreading use of internet enables it to be used in different fields and the field of education (13). It's reported that web-based education should also be supported due to immediate meeting of the information requirements of patients (14). Web-based applications enable fast and effective communication with the health professionals and have positive sides such as ensuring that the patient receives feedback and suggestion on time; thus, he/she provides the effective care in line with his/her requirements, the rural patients get in contact with the health professionals in home environment and decreasing time/transportation expenses $(6,15,16)$. Moreover, it's reported in the studies carried out that communications between diabetes team and individuals with diabetes by phone and applications of short message service (SMS) by cellular phones increase compliance to treatment of diabetes and enhance glucose control (17-19).

The purpose of this study is to research the effects of counselling services offered to individuals with diabetes by diabetes team via communication networks (internet, phone) on diabetes control.

\section{Methods}

The study was carried out between June 2015 and January 2016 at the Gazi University Pediatric Endocrinology Department. The Telehealth system was developed by the diabetes team and the demographie characteristics, frequency of use and HbA1c changes of type 1 diabetic patients using this communication network were noted. In the study, a telehealth system was developed by a pediatric diabetes team (nurse, dietitian, psychologist, medical doctor) and counsellings made via communication networks (internet, smart phones) for the last 6 months were analyzed. Counselling hours were scheduled as 11:30-14:30 and 21:00-24:00 hours by the diabetes team in the telehealth system.

The purpose of the study was explained to each participant and written informed consent was obtained. The study procedures were in accordance with the Declaration of Helsinki. Prior to the research, the families consented the statistical analysis that was going to be administrated on the nourishment, blood glucose testing results, insulin doses, physical exercises, and conversations about technical issues, except confidental communications between the researchers and families.

The analyses were based on variables such as call frequency, number of years of being a patient with diabetes, use of infusion pump, carbonhydrate count. People calling every day, 5 to 6 times a week, once to twice a week, once every 15 days were identified as frequent ealler group while people calling once a month, every 2 months, once every 3 months were identified as infrequent caller group.

Demographic characteristics and information about diabetes were saved from patient files. Hemoglobin A1c (HbA1c) levels at baseline and at follow-up were evaluated.

\section{Statistical Analysis}

Statistical analyses were carried out by using SPSS package. Average standard deviation in percentage comparison, Chi Square test in percentage comparison and repeated measure t-test in paired comparison were used respectively. Differences in case of $\mathrm{p}<0.05$ were accepted as significant.

\section{Results}

The study was carried out on participants varying between the ages of 2 and 18 who were $(10.89 \pm 4.00) 43$ girls $(52.4 \%), 39$ boys $(47.6 \%)$. When the girl and boy participants were compared in terms of age variable, no statistically significant difference was obtained ( $p>.05)$. Thus, it can be said that the source of difference is not the age

It was determined that out of the participants $11(13.4 \%)$ were newly diagnosed with diabetes, $36(43.9 \%)$ were patients with diabetes for 1 to 3 years, $19(32.3 \%)$ were patients with diabetes for 4 to 6 years, $16(19.5 \%)$ were patients with diabetes for 7 and more years. In the study, out of the children $14(17.1 \%)$ had pump therapy while $59(72.0 \%)$ counted carbonhydrates. It was determined that out of the participants $78(95.1 \%)$ came for check-up regularly; while $11(13.4 \%)$ went into ketoacidosis after the diagnosis.

Parent's data (both mother and father) were given in Table 1.

In Table 2, the communication network used by children, the people who contacted with the diabetes team for getting counselling service, frequency of counselling, the most consulted diabetes team and counselling subject headings were specified.

As is seen from Table 2, the individuals with diabetes or their families prefer Whatsapp which is an instant messaging application at most $(57.3 \%)$, contact with diabetes education nurse at most $(32.9 \%)$ and consult with the diabetes team about insulin dosesand blood glucose regulation at most (42.7\%). Moreover, frequency of counselees calling 7 times a week $(28.0 \%)$ was found higher than the other frequency of counselling. 
In analysis of Table 3, when HbA1c levels were compared as per call frequency of individuals with diabetes or their families (comparison of individuals calling every day, few times a week and every 15 days with those calling once a month, every 2 months, once every 3 months) by using repeated measure t-test, it was determined that $\mathrm{HbA1c}$ values after 6 months were lower in those individuals calling frequently $(\mathrm{p}<0.001)$.

When Table 4 was analyzed, it was determined that HbA1c levels of the individuals with diabetes consulting with the diabetes team by using telehealth method decreased after 6 months significantly. It was seen that $88.9 \%$ of 36 individuals with diabetes whose HbAlc value was below $7.5 \%$ consulted frequently while $76.9 \%$ of 26 individuals whose $\mathrm{HbA1c}$ value was $9 \%$ consulted rarely.

\section{Discussion}

The use of communication technologies in providing healthcare services increases the communication of individuals living in far places from health centres and the barriers of patients to get healthcare service are removed (20). Telehealth system is a system including forms of information transfer such as audio, image, speech, video; communication technology such as phone line, satellite connection, cellular phone. This systen provides duplex audiovisual communication between health professionals and patient (21). In this study, the communication of the individuals with Type 1 diabetes and their families with the diabetes therapy team via whatsApp, phone and SMS was investigated. Accordingly, it was determined that the diabetes therapy team was contacted at most via whatsApp; an intermessaging and file transfer/sending program via internet (57.3\%), and phone (23.2\%) (Table 2). Internet which is used in numerous fields also supports the field of education. It's thought that the reason why the children and their families prefer whatsApp is that they can easily communicate with the diabetes team via SMS, voice mail system, audio and video call by using the wifi of phone and can immediately share the photos showing their blood glucose values. In this study, it's determined that the mothers of individuals with diabetes $(64.6 \%)$ and adolescents with diabetes $(24.4 \%)$ themselves communicate with the diabetes team at most (Table 2).

According to the American Diabetes Association (ADA) report (2014), it's emphasized that the acute and chronic complications of diabetes can be prevented or delayed by individuals with diabetes receiving educations regarding self-management and being supported regularly (22). Children and adolescents with Type 1 diabetesoriented educations increase the quality of life and glycemic control to an optimal level (23). However, the educations of individuals with diabetes being continuously, frequently and repeatedly more effective in terms of glycemic control (24). Thus, telehealth system has started to be used in treatment of chronic diseases such as diabetes in recent years due to its flexibility and cost effeciency. The patients can be aided by one-to-one education, social support and self-management thanks to this system (25). In this study, a decline in HbA1c values was observed as the frequency of consulting with the diabetes team increased (Table 3). While the initial HbAlc averages of frequent callers were $8.30 \pm 1.16 \%$, their HbA1c averages after 6 months decreased to $7.45 \pm 0.87 \%$. While the initial HbA1c averages of rare calling group were $9.10 \pm 1.26 \%$, their HbA1c averages after 6 months increased to $9.28 \pm 1.25 \%$. In the study carried out by Thompson et. al., the individuals with Type 1 diabetes were contacted by phone for 15 minutes for 3 weeksand during this time, the diabetes nurse provided insulin dose adjustments of the individuals with diabetes. In this study, significant declines in HbA1c values of the individuals with diabetes at the end of 6 months were achieved likewise our study results (26). In the Diabetes Control and Complications study, significant improvements in HbAlc values were determined when the individuals with diabetes visiting the research centre once a month and communicating by phone regularly were compared with the control group (27). Another study in which diabetic patients reached the diabetes team using SMS and the internet reported a significant decrease in HbA1c values after 3 months (28). Likewise, in the study carried out by Bin-Abbas et. al. daily information messages regarding the procedures related to diabetes care, weekly interactive messages and optional multimedia messages were sent to the individuals with diabetes. As a result of the study, it's reported that significant decreases in postprandial glucose and HbA1c levels, followup frequency of basic hypoglycemic attack and blood glucose were observed (29).

It's reported that web-based telehealth services improve patient satisfaction, patient's compliance to diabetes treatment and clinical results $(29,30)$. It's stated that telehealth systems including individualized evaluations, supervision and skills development by feedback are more effective in improvement of glycemic control. In this study, it's determined that the most consulted therapy team is the diabetes nurse and the most consulted issue is insulin dose and blood glucose regulation follow-up (42.7\%). These are followed by carbonhydrate count $(29.3 \%)$, actions to be taken in case of hyperglycemia and hypoglycemia $(17.1 \%)$, methods of insulin injection to be applied in different food consumption, technical problems in instruments (pump failure, message failure, battery running out, set change, blockage in set and etc.), insulin dose and eating system adjustment (10.1\%) on special days (birthday, wedding, picnic and etc.) and in special cases (fever, diarrhea and vomiting and etc.) respectively (Table 2 ). In this study, the diabetes team making suggestions and reminding, giving education information and giving online support to the individuals with diabetes for 6 months caused the continuity of communication with the individuals with diabetes, the patients to develop self-control and thus, ensured that the changes in the patient's status were early detected and intervened and supported the individuals with diabetes with management of their diseases. It was seen that $88.9 \%$ of 36 individuals with diabetes whose HbA1c value 
after 6 months was below $7.5 \%$ called frequently while $76.9 \%$ of those whose HbA1c value was above $9.5 \%$ called rarely (Table 4).

\section{Study limitation}

The short duration of the study and the limited number of cases constitute the limitations of the study. Other limitations that the our telehealth system is not institutional and is not accessible 24 hours a day.

\section{Conclusion}

Increase in consulting with the diabetes team provided the blood glucose controls of the individuals with diabetes. The guidelines published in recent years suggest individualized treatment and a multidisciplinary approach in diabetes management. Telehealth system developed by the diabetes team is a useful system in early detection and intervention of changes in the individual's status, enhancing the patient's self care.

There is a need for institutional system for a regular and functioning service. The system should allow the whole team to access and monitor the patient's entries simultaneously for a synchronized intervention.

\section{Ethics}

Ethics Committee Approval: The study was approved by the Gazi University Local Ethics Committee (approval number: it will be reported later)

Informed Consent: Consent form was filled out by the parents of all children and adolescent

Authorship Contributions

MedicalPractices: Esra Döğer, Aylin Kılınç Uğurlu, Emine Demet Akbaş, Aysun Bideci, Orhun Çamurdan, Peyami Cinaz, Concept: Esra Döğer, Şebnem Ercan, Rukiye Bozbulut, Şebnem Soysal Acar, Design: Esra Döğer, Rukiye Bozbulut, Şebnem Soysal Acar, Data Collection or Processing: Şebnem Ercan, Rukiye Bozbulut, Şebnem Soysal Acar, Analysis orInterpretation: Şebnem Soysal Acar, Rukiye Bozbulut, Esra Döğer, Literature Search: Rukiye Bozbulut, Esra Döğer, Emine Demet Akbaş, Aylin Kılınç Uğurlu,Writing: Rukiye Bozbulut, Esra Döğer, Şebnem Soysal Acar, Emine Demet Akbaş.

Financial Disclosure: The authors declared that this study received no financial support.

\section{Disclosure Statement}

The authors have no conflicts of interest to declare.

\section{Acknowledgments}

We thank all patients and their parents for participating in this study.

\section{References}

1. Nylander C, Tindberg Y, Haas J, Swenne I, et al. Self-and parent-reported executive problems in adolescents with type 1 diabetes are associated with poor metabolic control and low physical activity. Pediatric Diabetes 2017;https://doi.org/10.1111/pedi.12520

2. Ayatollahi H, Hasannezhad M, Fard HS, Haghighi MK. Type 1 diabetes self-management: developing a web-based telemedicine application. Health Information Management Journal 2016; 45(1): 16-26.

3. Kwon HS, Cho JH, Kim HS, Lee JH, Song BR, Oh JA, Son HY. Development of web-based diabetic patient management system using short message service (SMS). Diabetes Research and Clinical Practice 2004; 66: 133-137.

4. Lange K, Swift P, Pankowska E, Danne T. Diabetes education in children and adolescents. Pediatric Diabetes 2014; 15 (20): 77-85.

5. Silverstein J, Klingensmith G, Copeland K, Plotnick L, Kaufman F, Laffel L, Clark N. Care of children and adolescents with type 1 diabetes. Diabetes care $2005 ; 28(1): 186-212$.

6. Azar M, GabbayR. Web-based management of diabetes through glucose uploads: Has the time come for telemedicine? Diabetes Research and Clinical Practice 2009; 83: 9-17.

7. Kim HS. A randomized controlled trial of a nurse short-message service by cellular phone for people with diabetes. International journal of nursing studies,2007; 44(5): 687-692.

8. Tao D, Or CKL. Effects of self-management health information technology on glycaemic control for patients with diabetes: a meta-analysis of randomizedcontrolled trials. Journal of Telemedicine and Telecare 2013; 19: 133-143.

9. Heidgerken AD, Lewin AB, GeffkenGR, Gelfandw KM, Storch EA, Malasanos T. Online diabetes education: design and evaluationwith prospective diabetes camp counsellors. Journal of Telemedicine and Telecare 2005; 11: 93-9.

10. Newton KT, Ashley A. Pilot study of a web-based intervention for adolescents with type 1 diabetes. Journal of Telemedicine and Telecare 2013;19(8), 443-449.

11. Whittemore R, Jaser SS, Jeon S, Liberti L, DelamaterAet.al.AnInternet Coping Skills Training Program for Youth With Type 1 Diabetes. NursRes 2012; 61(6): 395-404. 
12. Esmatjes E, Jansa' M, Roca D, Pe'rez-Ferre N, Del Valle L, Martínez-Hervas S. et al. The Efficiency of Telemedicine to Optimize Metabolic Control in Patients with Type 1 Diabetes Mellitus: Telemed Study. Diabetes technology \& therapeutics 2014;16(7): 1-7.

13. Dougherty JP, Lipman TH, Hyams S, Montgomery K. Telemedicine for Adolescents With Type 1 Diabetes. West J Nurs Res. 2014;36(9):1199-221.

14. Nguyen HQ, Kohlman CV, Rankin SH, Slaughter R, Stulbarg MS. Internet-based patient education and support interventions: A review of evaluation studies and directions for future research. Computers in Biology and Medicine An International Journal2004;34(2): 95-112.

15. Kyngas H. Patient education: perspective of adolescents with a chronic disease. J ClinNurs 2003; 12 : 744-51.

16. Mcmahon GT, Gomes HE, Hohne SH, Ming-Jye Hu T, Levine BA, ConlinPR. Web-Based Care Management in Patients With Poorly Controlled Diabetes. Diabetes Care 2005; 28: 1624-1629.

17. Thompson DM, Kozak SE, Sheps S. Insulin adjustment by a diabetes nurse educator improves glucose control in insulin-requiring diabetic patients: a randomized trial. Canadian Medical Association Journal1999; 161(8): 959-962.

18. Baumer JH, Hunt LP, Shield JPH. Audit of diabetes care by caseload. Archives of disease in childhood1997; 77(2): 102-108.

19. Bin-Abbas B, Jabbari M, Al-FaresA, El-Dali A, Al-Orifi F. Effect of mobile phone short text messages on glycaemic control in children with type 1 diabetes. Journal of telemedicine and telecare 2014; 20(3): 153-156.

20. Öz F. SağlıkAlanındaTemelKavramlar. Hemşirelik. 2.Baskı, Ankara: MattekMatbaacılık, 2010: 44-48.

21. Miller EA. Solving the disjuncture between research and practice: Telehealth trends in the 21 st century. Health Policy 2007; 82: 133-141.

22. American Diabates Association (ADA). Standards of medical care in diabetes-2014. Diabetes Care 2014; 37(1): 14-80.

23. Abolfotouh MA, Kamal MM, El-Bourgy MD, Mohamed SG. Quality of life and glycemic control in adolescents with type 1 diabetes and the impact of an education intervention. Int J Gen Med 2001; 4:141-152. 24. International Society for Pediatric and Adolescent Diabetes (ISPAD). (2011). Global IDF/Ispad Guideline For Diabetes in Childhood and Adolescence: Diabetes in Adolecent. 6th. Edition.

https://www.ispad.org/sites/default/files/resources/files/idf-

ispad_diabetes_in_childhood_and_adolescence_guidelines_2011_0.pdf.Date accessed: 19.06.2014.

25. Franc S, Daoudi A, Mounier S, Boucherie B, Dardari D, Laroye H, Charpentier G. Telemedicine and diabetes: achievements and prospects. Diabetes \& metabolism 2011;37(6):463-476.

26. Thompson DM, Kozak SE, Sheps S. Insulin adjustment by a diabetes nurse educator improves glucose control in insulin-requiring diabetic patients: a randomized trial. CMAJ 1999;161:959-62.

27. The Diabetes Control, Complications Trial Research Group. The effect of intensive treatment of diabetes on the development and progression of long-term complications in insulin-dependent diabetes mellitus. N Engl J Med 1993;329:977-86,

28. Kwon HS, Cho JH, Kim HS, Lee JH, Song BR, Oh JA, Son HY. Development of web-based diabetic patient management system using short message service (SMS). Diabetes Research and Clinical Practice 2004; 66:133-137.

29. Bin-Abbas B, Jabbari M, Al-Fares A, El-Dali A, Al-Orifi F. Effect of mobile phone short text messages on glycaemic control in children with type 1 diabetes. Journal of telemedicine and telecare 2014; 20(3): 153-156. 30. Pérez-Ferre N, Galindo M, Fernández MD, Velasco V, de la Cruz MJ, Martín P Calle-Pascual AL. A Telemedicine system based on Internet and short message service as a new approach in the follow-up of patients with gestational diabetes. Diabetes research and clinical practice 2010; 87(2):15-17.

Table 1. Demographic data of parents.

\begin{tabular}{|l|l|l|}
\hline Age & Mother & Father \\
\hline Education & $36,1 \pm 5,9$ & $40 \pm 6,5$ \\
\hline Primary school & & \\
\hline Secondary school & $24(29,3 \%)$ & $14(17,1 \%)$ \\
\hline High School & $10(12,2 \%)$ & $7(8,5 \%)$ \\
\hline University & $30(36,6 \%)$ & $36(43,9 \%)$ \\
\hline
\end{tabular}




\begin{tabular}{|l|l|l|} 
Postgraduate education & $2(2,4 \%)$ & $3(3,7 \%)$ \\
\hline Working Status & & \\
\hline Working & $27(32,9 \%)$ & $82(100,0 \%)$ \\
\hline Housewife & $55(67,1 \%)$ & - \\
\hline
\end{tabular}

Values are given as mean \pm standard deviation or number of cases (column percent) 
Table 2: Communication features

\begin{tabular}{|c|c|c|}
\hline Communication network used & $\mathbf{n}$ & $\%$ \\
\hline WhatsApp & 47 & $57.3 \%$ \\
\hline Phone & 24 & $29.3 \%$ \\
\hline Short message service & 11 & $13.4 \%$ \\
\hline \multicolumn{3}{|c|}{ People who contact with diabetes team for getting counselling services } \\
\hline Mother & 53 & $64.6 \%$ \\
\hline Person with diabetes himself/herself & 20 & $24.4 \%$ \\
\hline Father & 7 & $8.5 \%$ \\
\hline Sister/Brother & 1 & $1.2 \%$ \\
\hline Teacher & 1 & $1.2 \%$ \\
\hline \multicolumn{3}{|l|}{ Frequency of counselling } \\
\hline 7 times a week & 23 & $28.0 \%$ \\
\hline 2 to 3 times a week & 22 & $26.8 \%$ \\
\hline Every 15 days & 16 & $19.5 \%$ \\
\hline Once a month & 13 & $15.9 \%$ \\
\hline Once every 3 months & 8 & \\
\hline \multicolumn{3}{|l|}{ Most consulted member of the diabetes team } \\
\hline Diabetes Education Nurse & 27 & $32.9 \%$ \\
\hline Nurse - Medical Doctor & 18 & $22.0 \%$ \\
\hline Nurse - Diabetes dietitian & 14 & $17.1 \%$ \\
\hline Medical Doctor - Nurse - Diabetes dietitian & 14 & $17.1 \%$ \\
\hline Nurse - Psychologist & 6 & $7.3 \%$ \\
\hline Nurse - Diabetes dietitian - Psychologist & 2 & $2.4 \%$ \\
\hline \multicolumn{3}{|l|}{ Counselling Subject Headings } \\
\hline Insulin dose and blood glucose regulation & 35 & $42.7 \%$ \\
\hline Carbonhydrate count & 24 & $29.3 \%$ \\
\hline Hyperglycemia and hypoglycemia & 14 & $17.1 \%$ \\
\hline $\begin{array}{l}\text { Spreading in pump } \\
\text { Technical problems in instruments } \\
\text { Doses and diet on special occasions } \\
\text { Insulin doses in cases of fever, diarrhea an }\end{array}$ & 9 & $10.1 \%$ \\
\hline
\end{tabular}


Table 3: HbA1c values as per frequency of calling

\begin{tabular}{|l|l|l|l|}
\hline $\begin{array}{l}\text { Frequency of Telehealth } \\
\text { Use }\end{array}$ & $\begin{array}{l}\text { Initial HbA1C } \\
\text { Average }\end{array}$ & $\begin{array}{l}\text { HbA1C Average } \\
\text { After 6 Months }\end{array}$ & p \\
\hline $\begin{array}{l}\text { Rare } \\
(\mathbf{n}=\mathbf{3 4})\end{array}$ & $9.10 \% \pm 1.26$ & $9.28 \% \pm 1.25$ & 0.172 \\
\hline $\begin{array}{l}\text { Frequent } \\
(\mathbf{n}=\mathbf{4 8})\end{array}$ & $8.30 \% \pm 1.16$ & $7.45 \% \pm 0.87$ & $<0.001$ \\
\hline
\end{tabular}

Paired T test was used for comparison

Table 4: Effect of Call Frequency (Rare - Frequent) On HbA1c Levels After 6 Months

\begin{tabular}{|l|l|l|l|l|}
\hline \multirow{2}{*}{} & HbA1c & p \\
\cline { 2 - 4 } & $<\mathbf{7 . 5 \%}$ & $\mathbf{7 . 5 - 9 \%}$ & $\mathbf{9 \%}$ & \\
\hline Frequent Call (n) & 32 & 10 & 6 & \multirow{2}{*}{$\mathrm{p}<0.001$} \\
\hline Rare Call (n) & 4 & 10 & 20 & \\
\hline
\end{tabular}

Chi Square test was used for comparison 